\title{
The Importance of Religious Orientation in Managing Stress
}

\author{
Dr. Shadiya Mohamed Saleh Baqutayan \\ Perdana School of Science, Technology and Innovation Policy \\ University Technology Malaysia International Campus \\ Jalan Semamarak, 54100, Kuala Lumpur, Malaysia \\ Tel: 60-3-2615-4623Ｅ-mail: shadiya@ic.utm.my
}

Received: December 8, $2010 \quad$ Accepted: January 12, $2011 \quad$ doi:10.5539/ijps.v3n1p113

\begin{abstract}
The study analyzes the academic stress among students. It aims at investigating the effectiveness of religious orientation in managing stress among them. The sample consists of 218 bachelor's degree students in Malaysia universities. The data were collected from stressful situations questionnaire, role strain measures, and Intrinsic and Extrinsic orientation. Frequency analysis was used to examine level of stress, strain, and religious orientation. The results indicated that students experience moderate level of stress, strain, and religious orientation. However, a significant means difference in the perception of male and female students toward the study variables.
\end{abstract}

Keywords: Stress management, Religious coping, Coping mechanisms

\section{Introduction}

Many people experience stress as they combine busy lives and the demands of study and or work while trying to also save time for friends and family. For some people, stress becomes almost a way of life. We all experience episodic stress as getting ready for a major exam, completing an important paper, perhaps getting ready for an important interview. However, a continuous "state" of stress should not become a way of life. We know that stress over a prolonged period of time can leads to certain health risks, to say nothing of the wear and tear that happens to relationships and general wellbeing.

Scientific measures the distress in college students is the dropout rate. Although nationwide figures are difficult to obtain in the United States, it is estimated that $50 \%$ of entering freshmen do not finish college four years later (Hirsch \& Keniston, 1970). Studies on college dropouts relate them to the aversive side of the "fight or flight" formula; that is, students, feeling a mismatch between themselves and their college, wish to distance themselves from the source of stress, the college environment (Falk, 1975; Hirsch \& Keniston, 1970; Katz, 1969).

\section{Theoretical Framework}

Not surprisingly, the workload of college is significantly more involved than the high school workload, and it comes with less hand-holding from parents and teachers. With challenging classes, scheduling issues to coordinate, difficult tests and other academic obstacles, coupled with the more independent nature of the college learning structure, many new and returning students find themselves studying long, hard hours.

While college freshmen face the most obvious challenges that usually involve leaving one's entire support structure behind, creating a new social network, dealing with being away from home for the first time and finding less parental support, most students face social stress. Finding and living with a roommate, balancing friends with school work (and often part-time jobs), and dealing with the dynamics of young adult relationships can all be difficult, and these challenges can lead to significant stress (Elizabeth S., 2008).

One model that is useful in understanding stress among students is the person-environmental model. According to one variation of this model, stressful events can be appraised by an individual as "challenging" or "threatening" (Lazarus 1966). When students appraise their education as a challenge, stress can bring them a sense of competence and an increased capacity to learn. When education is seen as a threat, however, stress can elicit feelings of helplessness and a foreboding sense of loss.

A critical issue concerning stress among students is its effect on learning. The Yerkes-Dodson law (1908) postulates that individuals under low and high stress learn the least and that those under moderate stress learn the 
most. A field study and laboratory tests support the notion that excessive stress is harmful to students' performance.

Students seem to be more emotionally vulnerable at examination times. Mechanic (1978) showed that within the American University system, examinations had a profound negative effect on students and their families. Hamilton (1955) argued that one of the possible explanations of the debilitating effect of test anxiety is that it generates trains of "internal" information or worry directed towards the likely effects of failure and that this detracts from task activity. When information generated by worrying about the test reduces the capacity available for performing the task, the result is that performance breaks down and the result becomes self-confirming. Breaking the test anxiety loop is therefore very important and may indicate that examination training should be an essential ingredient of undergraduate or graduate programs.

Strain is a term used to indicate excessive tension in a muscle or nerve unit. It's usually caused by an activity overload, or psychological adjustment, usually due to an emotional overload (Goldenson, 1984). The term "stress" and "strain" go together in the literature--strain is the indicator of stress. According to Khan (1989), strain refers to a person's maladjustive psychological, physiological, and behavioral responses to stress. It should be noted that the term "strain" and "tension" are often used interchangeably. However, the manifestation of strain can be seen in anxiety, depression, psychosomatic complaints, or in physiological changes in blood chemistry.

Stress can directly or indirectly affect almost all, if not all, the organic systems of the body; an example of an indirect effect is the exacerbation of a preexisting condition such as asthma (Magill, 1996). Another concern is the interrelationships among the myriad effects.

Even in the absence of deliberate conscious strategy to deal with stress. Individuals cannot remain in a continuous state of tension and emotional strain. The concepts of stress and coping are neutral. Although people commonly see stress as negative and coping as positive, the relationship is not that simple. Stress can be psychologically positive or negative, and the means of coping can be effective or ineffective in meeting the challenge presented by the stressful situation.

Psychologists (e.g., Pestonjee, 1992) have identified two major ways in which people cope with stress. In the first approach, a person may decide to suffer or deny the experience stress. This is the passive approach. Alternatively, one may decide to face the realities stress and clarify the problem through negotiations with other members. This is the active approach.

Researchers have grouped the ways students cope with stress into four categories. First, they may decide to confront stress by struggling to meet targets. Secondly, they could to detach them solve from the stressful situation. Thirdly, they may reduce their stress through religious activity. Finally, they may decide to accept their life as it is.

Since the present study examines the effectiveness of religious orientation in managing stress and strain among students, the focus will be on the third category. That is, individuals may use religion as a buffering process to reduce the level of stress and strain. According to Pargament (1985), religion has three roles in the coping process. Religion can serve (i) as a part of the elements of coping, (ii) as a contributor to coping, and (iii) as a product of coping.

\subsection{Theoretical Model}

Stress is any situation that evokes negative thoughts and feelings in a person. The same situation is not evocative or stressful for all people, and all people do not experience the same negative thoughts and feelings when stressed (Whitman, Neal A (1985).

The person- environment model is useful in understanding stress among students. According to one variation of this model, an individual can appraise stressful events as "challenging" or "threatening" (Lazarus, 1966). When students judge their education as a challenge, stress can bring them a sense of competence and an increased capacity to learn. When education is seen as a threat, however, stress can elicit feelings of helplessness and a foreboding sense of loss.

A classic study of stress among students defines stress as discomforting responses of persons in particular situations (Mechanic, 1978). This definition de-emphasizes stress in terms of the nature of the event and focuses on the meaning individuals give it. According to some Muslim scholars like Sadiq Hussain (1984), stress is in the nature of human being, and perhaps best regarded as a healthy and normal reaction that is likely to produce illness if prolonged. Severe stress to any individual who does not have the capacity to adapt himself or herself to it is a healthy risk. 
A recent study by Richaudde \& Sacchi (2001) indicated that coping includes behavior and thoughts employed by the individual to manage the stressing situation. Moreover, the relationship between religion and mental health is a topic about which much has been written in terms of pros and cons. In the early $20^{\text {th }}$ century, Sigmund Freud wrote about the deleterious effects of religion on psychological development and predicted that religion was an illusion that had no future. More recently, attorney Richard Yao founded a group named "Fundamentalists Anonymous" designed to help people overcome the so-called "emotional distress" of a conservative religious upbringing (Malony, 2001). Among this group are counselor Donald Slot, who titled his recent book "the dangers of growing up in a Christian home, and California Clergyman named Booth," who has appeared on a number of television talk shows warning the public about the bad effects of what he has termed "religious addiction" (Malony, 2001).

Islamic view point sees religion as faith "Iman", action "Amal", and worship "Ibadah" triple mandate. Adjustment to difficult circumstances appeared to be better predicted by religious coping than by general religious orientation (Pargament et al., 1990). Moreover, religious coping strategies showed differential relationships to the outcomes of various stressful situations (Zwingmann and Murken, 2000). More specifically, religious coping was helpful or harmful depending on the particular type of religious coping strategy employed. Thus, religious coping would appear to be an ambivalent phenomenon which does not automatically entail beneficial outcomes.

Higher order factor analyses have revealed that particular religious coping methods can be classified into two broad overarching patterns: positive and negative religious coping (Pargament et al., 1998). In general, positive religious coping strategies, which reflect a confident and constructive turning to religion for support, tend to be beneficial for people undergoing stressful life events (Ano and Vasconcelles, 2005). In contrast, negative religious coping strategies, those which reflect an engaging in religious struggle and doubt, are generally more maladaptive (Ano and Vasconcelles, 2005).

\section{Research Design}

The present inquiry is designed to examine the existing relationship between stress and religious orientation in university students. The exploratory study uses descriptive and quantitative terms to establish the degree of relationships between dependent and independent variables. Furthermore, the strength and magnitude of the relationships was also investigated, by highlighting a correctional study is a useful strategy in situations where experimental research is difficult (Vockel and Asher, 1995).

\subsection{Method and Procedure}

\subsubsection{Hypothesis}

H1: Higher level of stress is associated with higher level of strain among the students.

$\mathrm{H} 2$ : High religious orientation is associated with low level of stress.

H3: High religious orientation reduces the level of strain among the students.

H4: Religious orientation moderates the relationship between stress and strain among the students.

H5: Female students experience more stress/strain levels than male students do.

H6: Female students use more religious coping strategies than male students do.

H7: Malay students experience more stress than non-Malay students do.

H8: Malay students use more religious coping strategies than non-Malay students do.

\subsection{Population}

The population in this study was all students studying at public University in Malaysia. The respondents were encompassing all students, male and female students were randomly selected from those students.

\subsection{Sample}

The sample consisted of 218 male and female from the first to final year bachelor's students of ten departments in the IIUM. Of these, $74.3 \%(\underline{n}=162)$ were Malays and $22 \%(\underline{n}=48)$ were non-Malays; $3.7 \%(\underline{n}=8)$ were missing values. The non-Malay group was made up of students from India, Palestine, Sudan, Yemen, Thailand, Somalia, Gambia, Tanzania, Mauritius, Iraq, Bosnia, Kenya, Eritrea, Djibouti, Algeria, Guinea, Ghana, Bangladesh, Sri Lanka, Albania, Afghanistan, Jordan, Pakistan, USA, Syria, South-Africa, East-Timor, Indonesia, and Uganda. Moreover, $54.1 \%(\underline{\mathrm{n}}=118)$ of the sample were female and $45 \%(\underline{\mathrm{n}}=98)$ were male; $.9 \%$ $(\underline{\mathrm{n}}=2)$ were missing values. 


\subsection{Instruments}

The instruments of this study were as follow: Stressful Situation Questionnaire (SSQ), Role Strain Measure, and Intrinsic and extrinsic religious orientations.

\subsubsection{The questionnaire}

This questionnaire consists of four sections. Section one seeks demographic information of the respondents, section two measures academic stress, section three measures students problem, section four measures social support as follow:

- Demographic information. In this section, the students were requested to provide demographic information regarding age, gender (sex), nationality, and year of study.

- $\quad$ Academic Stress. The important section of these instruments comprised 20 items related to Academic Stress (apprehension in classroom and speech situations (ACSS--13 items) and apprehension of social and academic failure (ASAF--7 items)).

- $\quad$ Role Strain. This section asked the students to describe how they would feel at certain times. Dov (1982) developed the scale and it consists of 21 items, rated on a 5-point scale ranging from "never true" (1) to "very often true" (5). Each item refers to a particular role strain. The scale consists of items concerning somatic problems and psychological depression.

- Religious Orientation. This section asked students to indicate the religious orientation that they employed in their effort to reduce stress. Intrinsic and extrinsic religious orientations were assessed with 18 items of the Allport-Ross scale (1967). The scale measured two religious orientations: intrinsic orientation (IR--6 items) with a reliability of .85 and extrinsic orientation (ER--12 items) with a reliability of .65.

\subsection{Procedures}

The questionnaires were distributed to the students in library and university subject classes. to ensure campus wide sampling, university subjects are offered to all students, regardless of their year of study or study option. After obtaining approval from the lecturers of the selected classes, the researcher personally requested the students to complete the questionnaire containing the above measures. They were given detailed instructions about how to fill in the questionnaire and were assured of complete anonymity of their individual responses. The students were given about 20-25 minutes to complete the questionnaires. A total of 250 questionnaires were distributed, but only 218 were returned. The 218 ( 204 sample size or 93\% confidential level, De Vans 1997).

\subsection{Statistical Analyses}

The data were analyzed using the statistical package for social sciences (SPSS). The researcher employed an exploratory, descriptive approach in analyzing the data involving frequency counts and percentage analysis. The descriptive statistics were used to determine the prevalence of academic stress, level of strain among the students, religious orientation that was used as buffering process, the relationship between stress, strain, and religious orientation.

\section{Research Findings}

\subsection{Level of stress}

As illustrated in figure 1, the majority of the respondents experience slight and moderate level of stress. This indicates that academic stress is not severe; it is just reasonable and modest. However, being student, it is common to have moderate level of stress that pushes the student do their work and duties at colleges. In the absence of slight stress, students will not do their works. as being mentioned by Smith (1990). He submits that stress encourage us to do things. It gets us out of our chair, think about things differently, and seek solutions to problems. Sometimes it makes us sensitive to what others may think of us and our actions.

\subsection{Level of Strain}

Generally, the sampled students show slight and moderate level of somatic problem and psychological depression. This is due to the corresponding of stress noticeable among them. Stress and strain are correlated (see figure 2).

\subsection{Religious Orientation}

Majority of the students use considerable level of religious orientation, because of their slight and moderate level of stress as well as strain that they reported. However, these results are correlated to one another, but the 
correlation is not that strong and clearly evident (figure 3). The finding is however similar to the majority of the literature on religious orientation, where many studies have found evidence that religious orientation is reliably associated with mental health (Donahue, 1985; Koenig et al., 1998; McCullough et al., 2000; Pargament, 1997; Smith et al., 2003). In addition, recent research has found that those who are intrinsically religiously orientated appear to perceive themselves as having less stress, than those who lack this quality (Pollard \& Bates, 2004).

\subsection{Stress, Strain, Religious Orientation, and Gender Differences}

The result of this study shows that males reported slightly more stress, strain and religious coping mechanisms than female do. However, the mean differences between them are just small, the male are slightly higher mean score in all the study variables than female students do.

This outcome contradicts the study done by Beit-Hallahmi \& Argyle 1997, on the psychology of religion. The study shows that women scored significantly higher than men for the majority of the religious measures, with the exceptions of negative religious coping (in which men scored significantly higher than women) and extrinsic-personal orientation towards religion (where no significant difference occurs between sexes). The findings, that women scored higher than men on many of the religiosity measures used in the present study, are consistent with the general view that women are more religious than men (figure 4).

\subsection{Stress, Strain, Religious Orientation, and Race}

There is no much difference between Malay and Non-Malay students' mean score in the entire study variables. Nevertheless, the Malay showed slightly higher mean score in stress, strain and coping mechanisms than non-Malay groups do (figure 5).

\section{Discussion}

The result of this study contradicts the notion that religious orientation is associated with psychological distress proposed by Seybold and Hill (2001). The proposion links religion or spirituality to mental and physical health status. These data also fail to provide evidence on the notion that religiosity buffers the impact of stress and strain on psychological distress among students. These findings add further weight to the recent work conducted by Maltby et al. (1999) who suggests that the core mechanism moderating the relationship between religiosity and psychological well-being depends personal religious practice. They found that frequency of personal prayer (and not a measure of religious orientation) was the dominant measure of significance of the variance in depressive symptoms, trait anxiety and self-esteem. Therefore, it is reasonable to conjecture that the absence of an association between religiosity and psychological distress in the present study may be accounted for by the lack of sensitivity of the religious measure employed. If this is indeed the case, these data are noteworthy as they highlight the beneficial impact of personal religious practice rather than religiosity per se. This view is also consistent with the work of Pargament (1997), who argues that religiosity should not be considered as a simple dimension. Instead, it should include religious acts such as personal prayer and church attendance - in this way religion permeates all aspects of life. For example, there is evidence that church attendance buffers against suicide (O'Connor \& Sheehy, 2000).

According to O'Connor D. B. et al (2001) within the general stress-health literature, it is important to bear in mind that measures of psychological constructs may not always be as applicable and apposite within a student sample as they are to a general population. In the research sample, the males reported slightly high levels of stress, strain and religious orientation compared to the female sample and these findings are inconsistent with study conducted elsewhere (e.g. Lewis et al., 1998). Therefore, it may be the 'irreligious' nature of the present sample, which accounts for the absence of an association between religiosity, stress and psychological distress.

\section{Conclusion}

This study has managed to explore the complex concepts of religion and stress. It has found that religious orientation is slightly correlated to academic stress. While most previous research on the subject, indicates evidence of association between good mental health and well-being occasioned by religious faith. Generally, the research has focused on acute mental and physical illness, and it is possible that the daily pressure/stress experienced by students may not be sufficiently stressful for them to turn to religion for remedy. Therefore, this sight correlation between stress and religious orientation among students is greatly accepted in this study. Perhaps religion is more likely to be used in coping with major traumatic stressors relative to daily hassles (Plante et al., 2001).

This preliminary exploratory study of the relationship between religious orientation and perceptions of stress and strain as is a basis for future research into this field due to the variety of conceptual and methodological difficulties associated with a research of this nature. Further research is required to clarify and elaborate on the 
role of religion in the perception of academic stress. The role of gender in the perceptions of religious orientation, stress and strain, respectively would also require further exploration.

The relevance of religion in students' ability to cope with stress seems to be dependent up their perception of their respective faith. If a candidate limits religion to a matter of orientation (mere line of thought, with nominal action), then the capacity of influence his/her level of stress is low. On the contrary, a faithful devotee is relieved of his stress by engagement in religious rites.

Undergraduate students experience appreciable level of stress and strain-due to academic challenges. However, religious orientation seems to be adopted as coping mechanism by majority of students. Unfortunately, the research outcome suggests the correlation of variables, but contradicts similar studies on the subject.

\section{References}

Ano, G. G., and Vasconcelles, E. B. (2005). Religious coping and psychological adjustment to stress: A meta-analysis. J. Clin. Psychol, 61: 1-20.

Beit-Hallahmi, B., and Argyle, M. (1997). The psychology of religious behavior, belief and experience. Routledge, London.

Carver, C. S., Scheier, M. F., \& Weintraub, J. K. (1989). Assessing coping strategies: A theoretically based approach. Journal of Personality and Social Psychology, 56 (2): 267-283.

Cohen, J. (1988). Statistical power analysis for the behavioral science. New Jersey: Lawrence Enlbaum Associates.

Donahue, M. J. (1985). Internal and Extrinsic religiousness: Review and meta-analysis. Journal of Personality and Social Psychology, 48(2), 400-419.

Elizabeth Scott, M.S. (2008). Stress In College: Common Causes of Stress In College.

Falk, D. (1975). Campus environment, student stress, and campus planing. In B. Bloom (Ed.), Psychological stress in the campus community. New York: Behavioral Publications.

Fisher, S. (1993). Stress in academic life. London: British Library.

Folkman, S., \& Lazarus, R. S. (1980). An analysis of coping in middle-aged community sample. Journal of health and social behavior, 21: 219-239.

Folkman, S., Lazarus, R. S., Gruen, R. J., \& Delongis, A. (1986). Appraisal, coping, health Folkman, S., \& Lazarus, R. S. (1985). If it changes it must be a process: A study of emotion and coping during three stages of a college examination. Journal of personality and social psychology; 48: 150-170.

Frey, C.U., and Rothlisberger, C., (1996). Social support in healthy adolescents. Journal of Youth and Adolescence, 25, pp. 17-31.

Goldenson, R. M. (1984). Longman dictionary of psychology and psychiatry. New York: Longman.

Hamilton, M.A., 1955. The assessment of anxiety states by rating. Br J Med Psychol 32, pp. 50-55.

Hirsch, S. J., \& Keniston, K. (1970). Psychological issue in talented college dropouts. Journal of Psychiatry, 33, $1-20$.

Hopkins, K. D., Hopkins, B. R., \& Glass, G. (1996). Basic statistic for the behavioral science. Boston: Allyn and Bacon.

House, J. S., Landies, K. R., \& Umberson, F. (1988). Social relationships and health. Science, 241: 540-550.

Hussain, S. (1984). Islamization of psychology. Third international seminar on Islamic thought. Malaysia: Kuala Lumpur.

Jones, J. (2003). Stress responses, pressure ulcer development and adaptation. British Journal of Nursing, 12: $17-23$.

Joseph, S., Williams, R., \& Yule, W. (1997). Understanding post-traumatic stress: A psychosocial perspective on PTSD and treatment. London: Wiley.

Khan, I. (1989). Job politics and intent to leave: An empirical test of fightflight responses to job stress. Unpublished doctoral dissertation, Magadh University, Bodh-Gaya, India.

Kidder, L. H., Judd, C. M., \& Smith, E. R. (1986). Research methods in social relations. New York: Rinehart and Winston. 
Koenig, H. G., George, L. K., \& Peterson, B. L. (1998). Religiosity and remission of depression in medically ill older patients. American Journal of Psychiatry, 155, 536-542. In Plante, T.; Saucedo, B. \& Rice, C. (2001). The Association between Strength of Religious Faith and Coping with Daily Stress. Pastoral Psychology, 49 (4), 291-300.

Leary, M. R. (1995). Introduction to behavioral research. Boston: Cole Publishing.

Lewis C.A., Shevlin M., Lloyd N.S.V and Adamson G. (1998). The Francis Scale of Attitude towards Christianity (Short Scale): exploratory and confirmatory factor analysis among English students. Journal of Social Behavior and Personality, 13, pp. 167-175.

Magill, F. N. (1996). International encyclopedia of psychology. Illinois University, Chicago.Martin, D. W. 1996. Doing psychology experiments. London: Brooks/Cole Publishing Company.

Maloney, B.A. (2001). Distress among the legal profession: What law schools can do about it. Notre Dame Journal of Law, Ethics, and Public Policy, 15, 307-331.

Maltby J. Lewis C.A., and Day L. (1999). Religious orientation and psychological well-being: the role of the frequency of personal prayer. British Journal of Health Psychology, 4, pp. 363-378.

McCullough, M. E., Hoyt, W. T., Larson, D., Koenig, H. G., \& Thoresen, C. (2000). Religious involvement and mortality: A meta-analytic review. Health Psychology, 19, 211-222.

Mechanic D. (1978). Students under Stress. A Study in the Social Psychology of Adaptation. University of Wisconsin Press.

O'Connor \& N. P. Sheehy, (2000). Understanding suicidal behavior. BPS Books, Leicester.

O'Connor D. B., Joanna Cobba, \& O'Connor Rory C. (2001). Religiosity, stress and psychological distress: no evidence for an association among undergraduate students. Journal of Personality and Individual Differences, 34 (2003) 211-217.

Pargament K.I. (1997). The psychology of religion and coping: theory, research and practice. Guildhall Press, London.

Pargament, K. (1997). The psychology of religion and coping: theory, research, practice. New York: The Guilford Press.

Pargament, K. I. (1985). God help me: Toward a theoretical frame work of coping for the psychology of religion. Journal for the Scientific Study of Religion, 2, 195-224.

Pargament, K. I., Ensing, D. S., Falgout, K., Olsen, H., Reilly, B., Van Haitsma, K., \& Warren, R. (1990). God help me: (I): Religious coping efforts as predictors of the outcomes to significant negative life events. Am. J. Community Psychol, 56: 519-543.

Pargament, K. I., Smith, B. W., Koenig, H. G., and Perez, L. M. (1998). Patterns of positive and negative religious coping with major life stressors. J. Sci. Study Relig, 37: 710-724.

Pestonjee, D. M. (1992). Stress and coping. New Delhi: Sage.

Phinney, J. S., \& Haas, K. (2003). The process of coping among ethnic minority first generation college freshman: A narrative approach. Journal of Social Psychology, 143(6): 707-726.

Pollard, L., \& Bates, L. (2004). Religion and perceived stress among undergraduates during fall 2001 final examinations. Psychological Report, 95, 999-1077.

Richaud de Minzi, M. C., \& Sacchi, C. (2001). Coping assessment in adolescents. Jurnal of Adolescence.

Selye, H. (1976). The stress of life. New York: McGraw Hill.

Seybold K.S., and Hill P.C. (2001). The role of religion and spirituality in mental and physical health. Current Directions in Psychological Science, pp. 21-24.

Smith, T. B., McCullough, M. E., \& Poll, J. (2003). Religiousness and Depression: Evidence for a main effect and a moderating influence of stressful life events. Psychological Bulletin, 129, 614-636.

Vockel, E. L. \& Asher, J. W. (1995). Educational research. Englewood Cliffs, New Jersey: Prentice-Hall.

Whitman, Neal A (1985). Student Stress: Effects and Solutions. Association for the Study of Higher Education. Clearinghouse on Higher Education, Washington DC.

Yerkes, R. M., \& Dodson, J. D. (1908). The relation of strength of stimulus to rapidity of habit formation. 
Journal of Comparative and Neurological Psychology, 18, 459-482.

Zwingmann, C., and Murken, S. (2000). Coping with an uncertain future: Religiosity and millenarianism. Archiv $f$ ur Religionspsychologie, 23: 11-28.

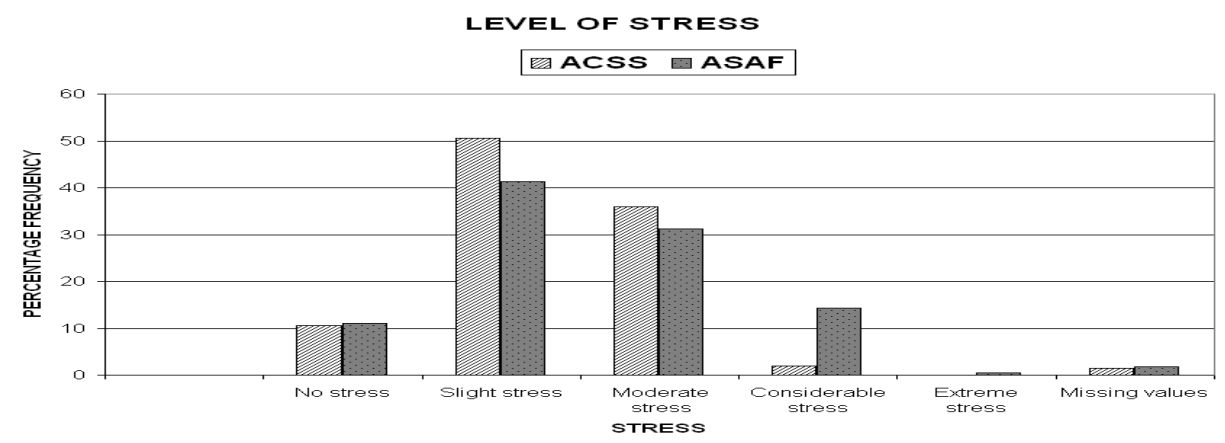

Figure 1. Stress Measurement

LEVEL OF STRAIN

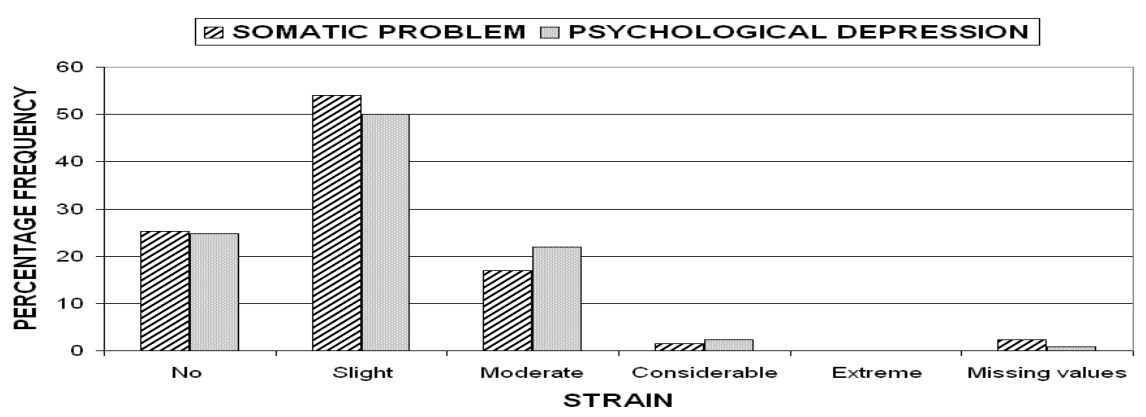

Figure 2. Level of Strain

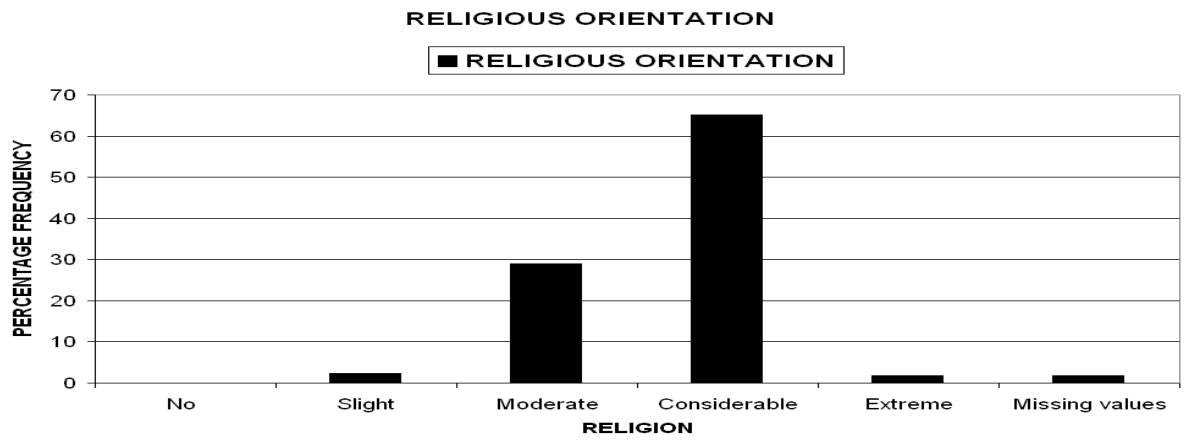

Figure 3. Religion Coping Mechanisms 


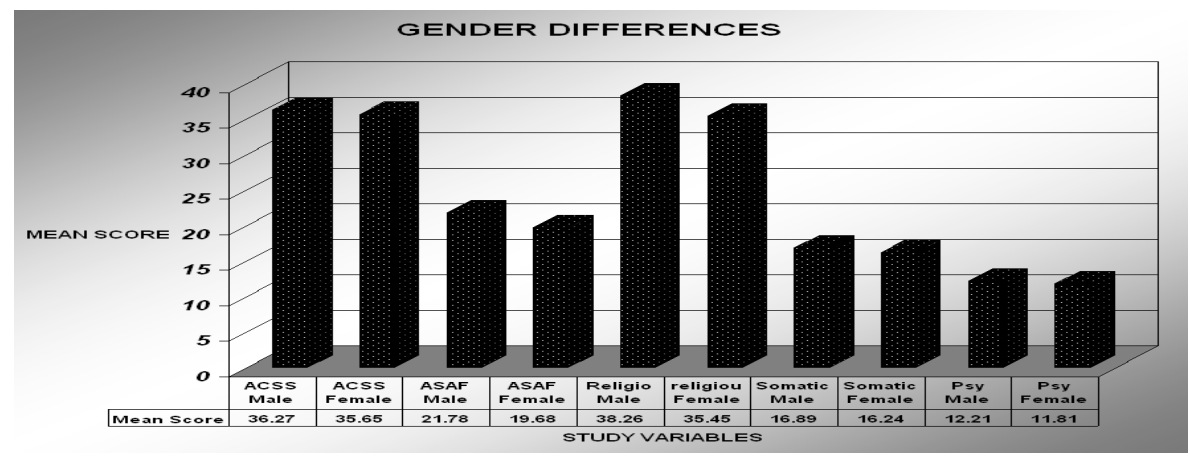

Figure 4. Gender Differences

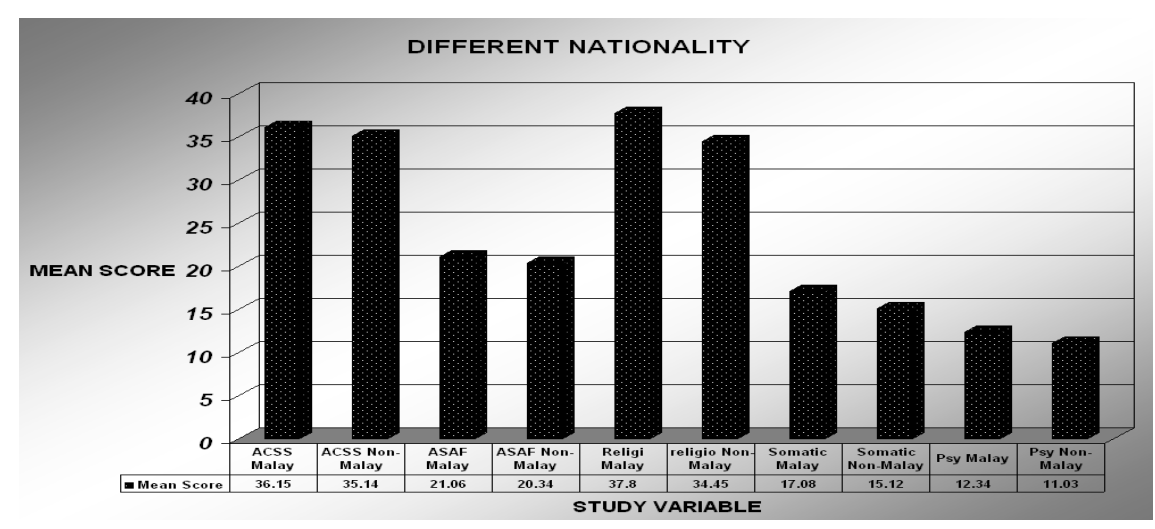

Figure 5. Nationality Differences 